\title{
Local Government ICT Platform Standardization Activities of ICT Systems and Services for Offering High Value-added Service by Interacting Local Governments, Regional Institutions and Private Sector
}

\author{
Akihira Yoshimoto, Shu-ichi Muto, Genichi Kaneda, Kazuaki \\ Ohara, Masahiko Nakayama, Atsushi Hirao, Hidekazu Masaki, \\ and Daisuke Miyamoto
}

The Association for Promotion of Public Local Information and Communication,

2-9-14, Torano-mon, Minato-ward, Tokyo 105-0001, Japan

\begin{abstract}
As Japanese local governments are facing severe financial situation, reduction of administration cost with use of ICT is in burning necessity. However, electronic local government has not been promoted smoothly in Japan, since ICT systems have been introduced without sufficient business process reengineering. On the other hand, the citizens' needs for enhancing public services have increased. In order to respond the citizens' needs with the fiscal constraint, enriching public online service by the service interaction between local governments and regional institutions and private sector is indispensable. The Association for Promotion of Public Local Information and Communication (APPLIC), its members are local governments and private companies, has promoted the standardization activities of Local Government ICT Platform, which enables smooth interaction of data and services and brings solutions to the problems. By applying the standard specifications, business operation in local governments will be streamlined, and local governments and regional entities will be able to provide high value-added services such as one-stop service to citizens. This paper describes problems Japanese local governments have regarding the public service utilizing the ICT, activity of APPLIC to establish and promote Local Government ICT Platform for alleviating the problems, and the effect and architecture of Local Government ICT Platform.
\end{abstract}

Please use the following format when citing this chapter:

Yoshimoto, A., Muto, S., Kaneda, G., Ohara, K., Nakayama M., Hirao, A., Masaki, H., Miyamoto D., 2008; in IFIP International Federation for Information Processing, Volume 286, Towards Sustainable Society on Ubiquitous Networks, eds. Oya, M., Uda, R., Yasunobu, C., (Boston: Springer), pp. 315-326. 


\section{Introduction}

In Japan, as aging society with fewer children proceeds, realization of the rich and collaborative society is aspired, which citizens and companies in region can share their knowledge and know-how, and esteem individual value and lifestyle.

By the progress of building of IT infrastructure based on e-Japan Strategy, ubiquitous network society has come that anyone can use ICT for anything always at anywhere. ICT also plays important role for the management of private companies and governmental agencies. In recent years the Japanese central government has carried out measures to realize "one-stop electronic administration for citizens" and "regional revitalization". Major measures are described in Table $1.1[1,2,3,4,5,6,7,8]$.

Table 1.1. Japanese government measures for e-government and e-local government

\begin{tabular}{|c|c|c|}
\hline Published Date & Document Title & Published Agency \\
\hline January 2006 & New ICT Reform Strategy & IT Strategic Headquarters \\
\hline March 2007 & New e-Municipality Promotion Guideline & $\begin{array}{l}\text { Ministry of Internal Affairs } \\
\text { and Communications }\end{array}$ \\
\hline April 2007 & $\begin{array}{l}\text { ICT Policy Package of New IT Reform } \\
\text { Strategy }\end{array}$ & IT Strategic Headquarters \\
\hline July 2007 & Priority Policy Program 2007 & IT Strategic Headquarters \\
\hline November 2007 & Regional Reproduction Strategy & $\begin{array}{l}\text { Headquarters for the Re- } \\
\text { gional Revitalization }\end{array}$ \\
\hline February 2008 & $\begin{array}{l}\text { Urgent Program for Regional Revitaliza- } \\
\text { tion by ICT }\end{array}$ & IT Strategic Headquarters \\
\hline April 2008 & ICT Policy Roadmap & IT Strategic Headquarters \\
\hline
\end{tabular}

However, electronic local government has not been promoted smoothly in Japan, since local governments have introduced the ICT systems without sufficient implementation of business process reengineering. On the contrary, the ICT systems based on procedures of conventional administrative office work that paper documents are centered, or the ICT systems that don't adequately meet the convenience and usability of citizens have established. In addition, due to the stagnation of the Japanese economy that has continued for years and hollowing out of domestic manufacturing in region, the tax revenue of local government has curbed. The subsidy from Japanese central government has also been cut along with the promotion of decentralization. Providing administrative service convenient for citizens by utilizing the ICT systems, under the circumstance of severe financial situation, is in burning necessity for the majority of local governments.

This paper presents the activity towards solving the problems Japanese local governments have regarding enhancing regional public services, with efficient use and expenditure of ICT systems. It is the activity to establish and promote Local Government ICT Platform, which is the standard specification documents for interacting and combining various services on network and building new services, based on the concept of Service Oriented Architecture (SOA). The goal of the activity is to streamline business operation in the local governments with minimum administrative costs and 
enhance convenience of citizens, by offering interactive public services such as onestop service. One-stop service is defined as the service conducted and terminated by single application of service.

The content of the paper includes the problems the Japanese local governments face, the introduction of the association tackling the problems, and the effect, system and architecture of Local Government ICT Platform. The remainder of this paper is organized as follows: Section 2 shows the present situation and the difficulties of Japanese local governments. Section 3 shows the brief explanation of the association that forms and promotes Local Government ICT Platform. Section 4 shows the outline and the effect of the standard specification, and section 5 shows its architecture and functions.

\section{Current Problems of Local Government}

Local governments hold difficulties regarding offering proper administrative service and managing regions. The main problems are introduced in this section: improvement of public services, reduction of ICT costs, increase in efficiency of administrative affairs, and the promotion of ICT industry in region.

\subsection{Improvement of Public Services}

The explosive spread of the Internet enables citizens to receive various services through the Internet. However, regarding administrative services, offering of services with the viewpoint of convenience for citizens has not sufficiently achieved, and the realization of high value-added public service is long awaited.

The typical example of high value-added public service is one-stop service, which the citizen can automatically receive the information regarding the administrative services related to the citizen, and can simultaneously apply applications not only to central and regional governments but also to regional institutions and companies from regional portal site. The one-stop service boosts the convenience of citizens especially at the time the major events in lifetime, such as moving, marriage, birth of child, death of relevant and retirement.

\subsection{Reduction of ICT Costs}

Many local governments apply general-purpose computers to ICT systems conventionally. General-purpose computer adopts centralized system and the process and management of data is done at central computer. As the years have passed, system modification in accordance to law amendment and addition of system functions has repeated, and inside of the general-purpose computer has become black box that system engineers cannot easily understand and modify the ICT system.

Since the number of the engineers who are able to maintain the general-purpose computer has decreased, concern regarding the stability of the maintenance work comes up and the operation and maintenance cost has increased. 
Furthermore, it is almost impossible for the other system vendors to reconstruct the system, since there is no designing standard for general-purpose computer. As the system vendor who is able to modify the ICT system is restricted to the original constructor, competition does not exist and the reduction of ICT system cost is difficult to occur.

Even though reconstruction of general-purpose computer and interaction between other systems are realized, they further increase the dependence to the original constructor, as specification of the system depends on the vendor. The effort of continuous use of system inhibits construction of ICT system that multiple system vendors participate in, and impedes proper procurement.

\subsection{Increase in Efficiency of Administrative Affairs}

Local governments used to develop systems optimal only for specific business, and there are many cases that the adopted technologies differ depend on system vendors or the timing of procurement. It makes the interaction between ICT systems difficult, and causes double input and double management of data. For instance, when a family moves in to the region and turns in application forms to a number of divisions of the local government, every division needs to input the same data such as name and address, since the interoperability of data is not achieved. Similarly, the employee of the local government has to ensure data consistency between the ICT systems of different divisions in certain intervals.

The interaction of data has not achieved until today, and the double input and double management of data causes inefficiency of the administrative office work.

\subsection{Promotion of ICT Industry in Region}

Many of system vendors in region have had few opportunities to acquire the information regarding measure of informatization that central and local governments promote. In many cases they tend to get subcontracted work of system construction, and are not in the situation of actively taking part in informatization in region, including construction of electronic local government. It is desired that local governments enable to conduct procurement more openly and with smaller unit, so that the opportunity of regional system vendors increases and it leads to employment expansion and economic growth of the region. 


\section{Formulation of Local Government ICT Platform by APPLIC}

Table 3.1. Vision, mission and major activities of APPLIC

\begin{tabular}{|l|l|}
\hline Vision & $\begin{array}{l}\text {-Collaborative promotion of regional community information policy by } \\
\text { public and private } \\
\text { - Building regional society which citizens get high value-added service by } \\
\text { the use of various ICT equipments }\end{array}$ \\
\hline Mission & $\begin{array}{l}\text {-Open and collaborative work by local governments and companies } \\
\text {-Interaction with policy of Japanese government }\end{array}$ \\
\hline Major activities & $\begin{array}{l}\text {-Drastic reform of information system of local governments } \\
\text { - Building the ICT Platform which openly interacts information systems of } \\
\text { regional institutions and companies } \\
\text {-Maintenance and promoting public applications such as disaster preven- } \\
\text { tion, medical treatment, education, etc. } \\
\text {-Holding personnel training and seminars for the promotion of regional } \\
\text { community information } \\
\text {-Further maintenance of the public ICT networks and promotion of inter- } \\
\text { connection of the networks } \\
\text { - Construction of a public ICT network that connects all prefectures in Ja- } \\
\text { pan }\end{array}$ \\
\hline
\end{tabular}

Table 3.2. Major roles of APPLIC committees

\begin{tabular}{|c|c|}
\hline $\begin{array}{l}\text { The technical } \\
\text { committee }\end{array}$ & $\begin{array}{l}\text { - Establishment and management of Local Government ICT Platform } \\
\text { standard specification document from the viewpoint of business, technol- } \\
\text { ogy, interconnection and GIS }\end{array}$ \\
\hline $\begin{array}{l}\text { The application } \\
\text { committee }\end{array}$ & $\begin{array}{l}\text { - Formulation of recommended specifications that local governments } \\
\text { could commonly adopt such as disaster prevention, health and welfare, } \\
\text { education } \\
\text { - Formulation of data interaction specification }\end{array}$ \\
\hline $\begin{array}{l}\text { The diffusion } \\
\text { promotion com- } \\
\text { mittee }\end{array}$ & $\begin{array}{l}\text {-Planning, preparation, and presentation of seminars to promote the Local } \\
\text { Government ICT Platform } \\
\text {-Diffusion of knowledge and know-how and the training of talented people }\end{array}$ \\
\hline $\begin{array}{l}\text { The information } \\
\text { and telecommuni- } \\
\text { cations infrastruc- } \\
\text { ture committee }\end{array}$ & $\begin{array}{l}\text {-Share of the information on maintenance situation regarding information } \\
\text { and telecommunications infrastructure } \\
\text { - Examination of the promotion method regarding infrastructure mainte- } \\
\text { nance toward building regional public network and broadband network } \\
\text { all over Japan }\end{array}$ \\
\hline
\end{tabular}

In order to solve the problems described in section 2 by promoting the examination regarding the realization of electronic local government and the regional informatization, the Association for Promotion of Public Local Information and Communication (APPLIC) was established in 2006. The members of APPLIC are local governments, private enterprises and academic experts who voluntarily participate in the examination process. The vision, mission and major activities of APPLIC are described in Table 3.1 .

APPLIC specifically consists of four committees: the technical committee, the application committee, the diffusion and promotion committee, and the information and 
telecommunications infrastructure committee. The major roles are described in Table 3.2 .

In the technical committee, in order to realize the smooth interaction of data and service within and between the local governments, and to realize one-stop service in region, the examination and establishment of Local Government ICT Platform is taken place, and APPLIC has released its standard specification documents on its website. The outline and effect of Local Government ICT Platform is explained in the following section.

\section{The Outline and Effect of Local Government ICT Platform}

\subsection{The Outline of Local Government ICT Platform}

For bringing solutions to the problems explained in section 2, APPLIC has set up Local Government ICT Platform. Local Government ICT Platform establishes standard specification for interacting data and various services on the network and building new services, based on the concept of SOA. Local Government ICT Platform does not include the creation of the standard platform system itself [9].

Local Government ICT Platform is established based on the viewpoint of operation and technology of administrative services. It establishes the standard of the data exchanged and the standard of the technology of exchanging the data (Figure 4.1). By conforming to Local Government ICT Platform, regional institutions and private enterprises will be able to provide various services through portal sites, such as information offering service on certain topics and application processing service on the time of moving or other important events. The service provider interacts with local government, utility enterprises such as electricity and post office and public enterprises via online to process the applications received from citizens.

Procurement authority such as local governments and regional institutions utilize local Government ICT Platform, for examination of system configuration. System vendors utilize local Government ICT Platform too, for development of system products and solutions.

The activity of building and rebuilding systems or releasing products conforming to Local Government ICT Platform is beginning to spread. As of June 2008, the development of system conforming to Local Government ICT Platform is on the way in several advanced local governments, and several other local governments are making plans to apply the standard. They request information and proposal regarding development and modification of system based on the standard. 


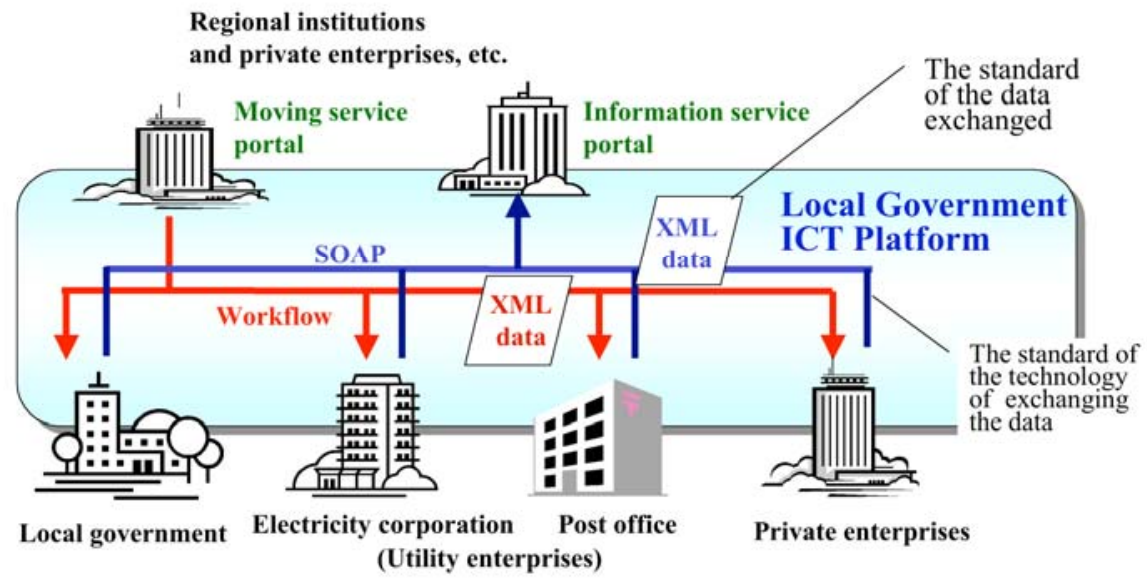

Fig. 4.1. Interaction between local governments, regional institutions and private sector by utilizing Local Government ICT Platform

There are more than twenty local governments that prepare budget for FY2009 to concern Local Government ICT Platform, and more than sixty local governments schedule to include budgeting in their medium-term plan. Also, there are 20 system vendors who have announced that they will release the products conforming to Local Government ICT Platform, and 12 consulting companies have announced that they can deal with consulting relates to the standard.

\subsection{The Effect of Local Government ICT Platform}

By adopting Local Government ICT Platform several effects will be brought to local governments and regions. In this section we describe two effects: electronic interaction within local government and one-stop online services between local governments and regional institutions and public sector.

\subsubsection{Electronic Interaction within Local Government}

The electronic interaction of business functions, such as receipt, process and approval, etc. of electronic application within the local government will be achieved by introducing Local Government ICT Platform. Conventionally, when citizen turns in several application forms to multiple divisions in local government, employee of each division punches in the information to its own ICT systems. The double input of information is one of the causes of inefficiency in administrative affairs. By realizing electronic interaction through Local Government ICT Platform, the workload of employee will be cut enormously. 


\subsubsection{One-stop Online Services between Local Governments, Regional Institutions and Private Sector}

Various service providers of the region will be able to interact electronically through Local Government ICT Platform, after the electronic interaction within the organization is realized. Regional portal site, which combines and provides various services, will appear, and citizen will be able to utilize the one-stop service only to access the regional portal site. Furthermore, high value-added service will be realized by interacting the several services different service providers provide. New business opportunity will also be created, as entrepreneurs set up regional portal site. Local government will be able to promote the regional portal site, by providing services itself or encouraging private sector of the region to develop regional portal sites.

\section{System, Architecture and Functions Regarding Local Government ICT Platform}

System of documents, architecture and its outline of functions regarding Local Government ICT Platform are described in this section.

\section{1 System of Documents Regarding Local Government ICT Platform}

Local Government ICT Platform standard specification consists of five specifications, one guideline and two other statements. System of documents regarding Local Government ICT Platform is shown in Figure 5.1.

As business model standard, Standard Specification regarding Local Government Business Application Unit regulates interface specification of major business application units required for the interaction of data and service. As service interaction technology standard, Standard Specification regarding Architecture and Standard Specification regarding Platform Communication regulates specification of requirements and protocol, etc. of platform applications that support service interaction. The version one of these standard specifications that aims for realizing the interaction within local government is released in 2007, and the version two that aims for realizing interaction between public and private sector is released in 2008 .

Specification regarding GIS Common Service regulates specification for building business units and applications utilizing GIS. Specification regarding Confirmation of Conformity and Interconnection regulates specification used to confirm conformity of various products and interconnection of the conformed products. These specifications are newly released in 2008 [10].

Guideline of Local Government ICT Platform compiles the matters, which should be concerned by procurement authorities who introduce service platform and business application conformed to Local Government ICT Platform.

Fundamental Statement regarding Local Government ICT Platform describes the basic concept and the aim of Local Government ICT Platform, and Operational Regu- 
lations regarding Local Government ICT Platform describes establishment, modification and release methods of the standard.

These documents are released at APPLIC website, and will be revised continuously.

\begin{tabular}{|c|c|c|}
\hline \multirow{4}{*}{ Specification } & Business model stan dard & Service interaction technology stan dard \\
\hline & $\begin{array}{l}\text {-Standard Specification regarding Local } \\
\text { Government Business Application Unit } \\
\text { interface specification of business application } \\
\text { unit required for the interaction of data and } \\
\text { information service providing by local } \\
\text { governments and public sector }\end{array}$ & $\begin{array}{l}\text {-Standard Specification regarding } \\
\text { Architecture } \\
\text {-Standard Specification regarding } \\
\text { Platform Communication } \\
\text { specificat ion of requirements and protocol, } \\
\text { etc. of platform application that support } \\
\text { service interaction }\end{array}$ \\
\hline & \multicolumn{2}{|c|}{$\begin{array}{l}\text {-Specification regarding GIS Common Service } \\
\text { specification for building business unit and application utilizing GIS }\end{array}$} \\
\hline & \multicolumn{2}{|c|}{$\begin{array}{l}\text {-Specification regarding Confirmation of Conformity and Interconnection } \\
\text { specification used to confirm conformity of various products and interconnection of the } \\
\text { conformed products }\end{array}$} \\
\hline Guideline & \multicolumn{2}{|c|}{$\begin{array}{l}\text {-Guideline of Local Government ICT Platform } \\
\text { guideline that compile the matters which should be concerned by procurement authorities who } \\
\text { introduce service platform and business application conformed to Local Government ICT } \\
\text { Platform }\end{array}$} \\
\hline $\begin{array}{l}\text { Other } \\
\text { statements }\end{array}$ & \multicolumn{2}{|c|}{$\begin{array}{l}\text {-Fundamental Statement regarding Local Government ICT Platform } \\
\text {-Operational Regulations regarding Local Government ICT Platform }\end{array}$} \\
\hline
\end{tabular}

Fig. 5.1. System of documents regarding Local Government ICT Platform

\subsection{Architecture and Functions of Local Government ICT Platform}

Architecture of Local Government ICT Platform is shown in Figure 5.2. Local Government ICT Platform consists of business units and service platform. Business unit consists of business unit interface necessary for interaction between business units, and business service interface necessary for realizing one-stop service. Service platform consists of platform communication function, integrated database function, business process management function and platform common function. The outline of these functions is described afterward.

The technologies applied in Local Government ICT Platform are separated into essential technologies and optional technologies. In order to realize one-stop service, different sites or differently implemented business units have to interact smoothly, so the essential technologies are the technologies indispensable to connect each site or business unit in communication level. They are specified based on the technologies formed by international standardization organizations such as W3C (World Wide Web Consortium) and OASIS (Organization for the Advancement of Structured Information Standards), and the conditions on which companies adopt the technologies to their products. Also, necessity for local governments is examined to specify the technological subset. Optional technologies are the technologies required depend on the service implementation requirements. They include technologies for reinforcing 
communication level depending on service requirements, and for realizing platform common functions necessary for connection between different sites.

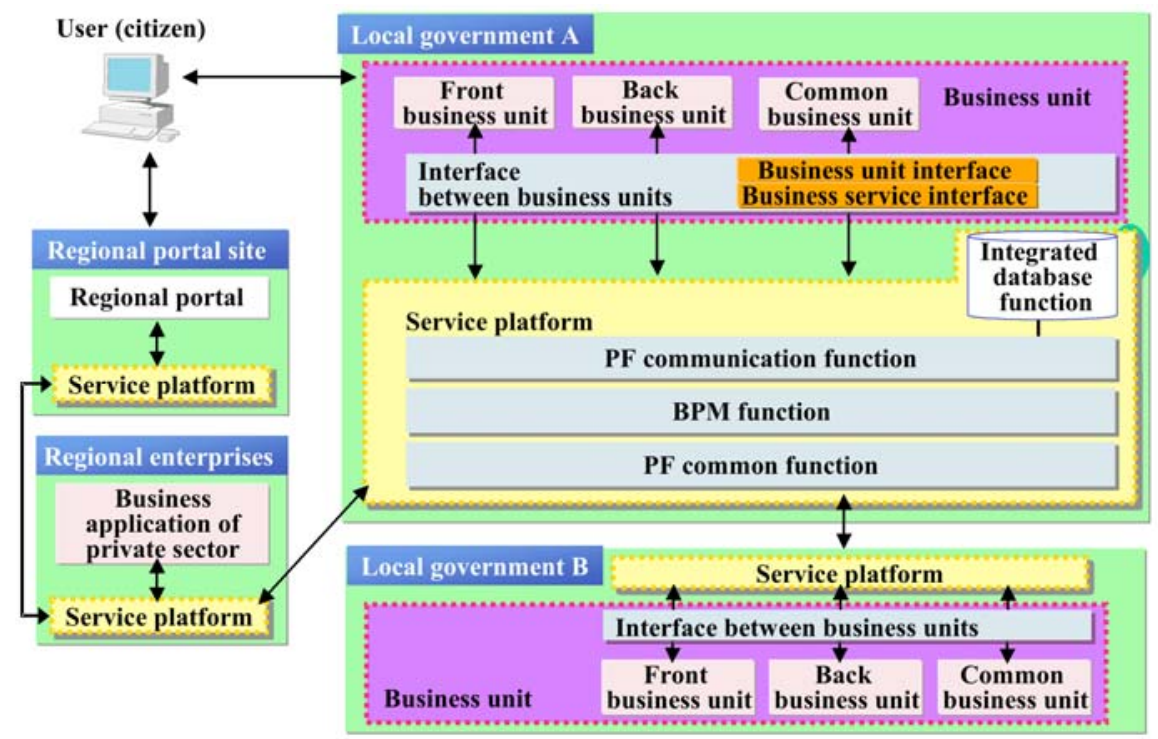

Fig. 5.2. Architecture of Local Government ICT Platform

\subsubsection{Platform Communication Function}

Platform communication function is service communication function based on international standard SOAP (Simple Object Access Protocol). Security and high reliability communication function, etc. can be applied as an option. Platform communication function serves as premise software of other system configuration units such as business units, business process management (BPM) function and integrated database function and does not compose system configuration unit independently.

The essential technologies of platform communication function are as follows: IPv4 for Internet protocol, SOAP1.1 for basic messaging, XML Schema1.0 for business documents definition, etc. The optional technologies of platform communication function are as follows: embedded text and SwA (SOAP messages with Attachments) for messaging with attachment files, SSL3.0, TLS1.0 for security of data transmission channel, etc.

\subsubsection{Integrated Database Function}

The integrated database is the mechanism that use and refer data unitary between business units. The platform communication function is the premise software, since information is offered from service call of SOAP to the integrated database. In order to interact with business units, it mounts the interface the standardized business unit mounts, which are necessary for interaction. There are two mounting methods: data- 
base system disclosure method and common interface method. Integrated database function is an option.

\subsubsection{Business Process Management Function}

BPM function manages execution of business process. It executes business process by calling service interface the business units offer, based on the business process definition determined on the basis of the international standard WS-BPEL (Web Services Business Process Execution Language Version 2.0). It has business service interface called by business units, the client of the business process execution. The platform communication function is the premise software, since the service communication is carried out. The BPM function is an option utilized in the case of executing sequential services one after the other, and is indispensable for offering one-stop service.

\subsubsection{Platform Common Function}

Platform common function is an option. The major technologies adopted here are monitoring function and service authentication and approval function, which have newly developed for the standard. Monitoring function is used to carry out process between multiple sites and to confirm the status of requested processing of the other site. The technology used here is the technology of collecting effective information in the case of avoiding processing troubles in advance, and formulating improvement of systems and services. Service authentication and approval function is used when the single sign-on is required between the sites that have different ID system. The technologies used here is the technology of preventing identification of multiple accounts under the same.

\subsubsection{Business Unit}

Business unit processes specific business independently. The platform communication function is the premise software, since the service communication is carried out. It has business unit interface, which is called from other business units or BPM function. It has business service interface, which is called from BPM function, in the case of realizing one-stop service interacting with BPM function. Some business units accept application and service from user or external organizations. They call for common business units, background business units or BPM function, and offer the result of processing.

\section{Conclusion}

In this paper we describe the necessity and efforts of establishing Local Government ICT Platform, in consideration of the policy of the Japanese central government and the problems Japanese local governments face regarding the promotion of electronic government. The outline of the specific standard is also introduced. We will 
continue promotion activities of Local Government ICT Platform and encourage local governments, regional institutions and system vendors to correctly understand its effect and adopt them. Operation, maintenance and enhancement of Local Government ICT Platform will also be conducted continually, based on the feedback we get from local governments and system vendors who adopt the standard.

\section{References}

1. IT strategic Headquarters, e-Japan Strategy, 2001.

2. IT strategic Headquarters, New ICT Reform Strategy, 2006.

3. IT strategic Headquarters, ICT Policy Package of New IT Reform Strategy, 2007.

4. IT strategic Headquarters, Priority Policy Program 2007, 2007.

5. IT strategic Headquarters, Urgent Program for Regional Revitalization by ICT, 2008.

6. IT strategic Headquarters, ICT Policy Roadmap, 2008.

7. Headquarters for the Regional Revitalization, Regional Reproduction Strategy, 2007.

8. Ministry of Internal Affairs and Communications, New e-Municipality Promotion Guideline, 2007.

9. The Association for Promotion of Public Local Information and Communication, Local Government ICT Platform fundamental description document V3.0, 2008.

10. The Association for Promotion of Public Local Information and Communication, Local Government ICT Platform standard specification document V2.0, 2008. 